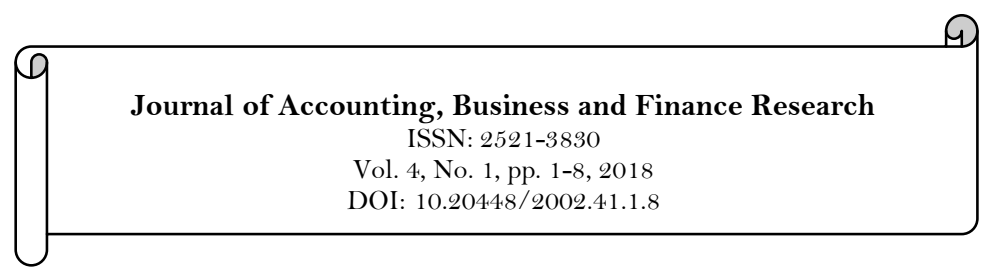

$\gamma_{\text {updates }}^{\text {check for }}$

\title{
An Analysis of the Development of China's Commercial Banks under the Structural Reform of the Supply Side
}

\author{
Chen $\mathrm{Zhu}^{1}$ \\ Liping Chen ${ }^{2 *}$
}

${ }^{1}$ Finance School of Nanjing University of Finance and Economics, China, Business School of Florida International University, U.S. ${ }^{2}$ School of Foreign Languages and Cultures, Nanjing Normal University, China.

Email: chenliping@njmu.edu.cn

\begin{abstract}
In recent years, with the acceleration of interest rate marketization in China, commercial banks are increasingly facing the business environment of increasing interest rate fluctuations, intensified competition among industries, and slowing down the growth of profitability. At the same time, in the past few years, the hidden credit risks behind the large-scale credit investment and high profits are gradually exposed, and the non-performing loan rate is rising. With the increasingly obvious drawbacks of demand-side management, supply-side reform emerges as the times require. Advocating innovation, adapting to consumption upgrading and guiding the optimization of export structure are its obvious advantages. As one of the main economic bodies, commercial banks should also clearly judge the current historical stage of their own. With the end of extensive economic growth, the expansion of commercial banks has ended, and a new historical turning point has arrived. The implementation of the structural reform on the supply side has put forward more explicit and specific requirements for the financial innovation of commercial banks. In this reform, commercial banks need to gradually establish a set of mechanisms, products and risk prevention system adapted to the new normal situation, and be able to flexibly use the relevant results to prevent and defuse the production capacity. This paper tries to analyze the opportunities and missions faced by commercial banks under the background of structural reform on the supply side, optimize the traditional development structure, sort out a new development framework, and give corresponding policy recommendations. We believe that commercial banks should take the initiative to support the supplyside reform while welcoming new opportunities for development. They should vigorously promote the growth of entrepreneurship finance, accelerate the development of Internet finance, dig deep into changes in customer demand, actively develop green finance, and optimize and adjust the credit structure of banks.
\end{abstract}

Keywords:

Supply-Side reform

Commercial banks

Credit structure

Financial innovation

Internet finance.

JEL Classification:

G21, G23, G26.

Licensed:

This work is licensed under a

Creative Commons Attribution

4.0 License.

Publisher:

Scientific Publishing Institute

\section{Introduction}

Under the new normal, China's macro-economy is still in a sustained downward trend. GDP growth rate in 2017 fell to $6.9 \%$ year-on-year, the lowest for 25 years, while the non-performing loan balance of commercial banks continued to grow for 17 quarters, and the non-performing loan rate continued to rise for 10 quarters. The real economy is in the throes of transformation and upgrading. There are three main sticking points in the current economic operation: 1) the lack of investment growth momentum. The total investment in new projects starting in November 2017 increased by only $1.8 \%$, down by $8.9 \% ; 2$ ) the market is difficult to achieve liquidation. The factory price of industrial products has been declining for 45 months; 3) excessive 
steel production capacity and employment pressure. Financial risk increase is also particularly serious. The core cause of the current economic downturn is structural and institutional, not external and cyclical, and the mismatch between supply and demand is the essence of the problem to be solved. Since current demand-side management cannot solve the economic bottleneck problem, it is necessary to explore the path of economic reform from the supply side (Jia \& Su, 2014).

In November 2015, the Central Government first introduced the "Strengthening the supply-side structural reforms", demonstrating that China's economic regulation has undergone a historic transformation. It will focus on creating new economic growth points and driving forces based on the improvement of the supply system to promote domestic economic restructuring and upgrading, and keep continuous healthy growth (Cao \& Li, 2015; Che, 2015; Zhao, 2015). While the downward trend of the macro economy continues to highlight, the implementation of supply-side reforms is in line with the internal needs of economic transformation and upgrading. Supply-side structural reforms can achieve economic structural upgrading and resource optimization by adjusting production factors such as labor force, land, capital, and innovation. The reallocation will increase overall factor productivity and further improve the quality and quantity of economic growth.

Commercial banks in the core position of economic and financial systems have significant Procyclical characteristics. In "the new normal state", the rapid expansion of commercial banks has ended. In the past three years, the non-performing loans of commercial banks have continued to increase. By the end of September 2017, the non-performing loan balance and non-performing loan rate of listed banks in China still showed a "double-rising" trend, in which the non-performing loan balance increased by more than 239.6 billion yuan compared with the end of 2016, and the non-performing loan rate increased to $1.58 \%$. When the domestic banking industry's new and old growth momentum fails to catch up, commercial banks should seize the opportunity of deepening the reform on the supply side to accelerate the transformation, timely and accurately position the role played in the reform on the supply side, actively adjust to speed up their own transformation and upgrading, take the initiative to promote the in-depth implementation of the reform on the supply side (Lu \& Liu, 2014). Therefore, making full use of the leading effect of commercial banks and actively cultivating and creating new supply and new power is not only the only way for commercial banks to deepen reform, accelerate transformation and maintain growth, but also an important link in the process of China's macroeconomic supply-side reform.

\section{Development Opportunities of Commercial Banks in the Context of Supply-Side Reforms}

Just when China's extensive economic growth phase has ended, the expansion of commercial banks has also ended. They should soberly judge the characteristics of the current situation. At present, the economic dividend has been weakened, the system dividend has been eliminated, and the cost advantage is no longer present. It is wise to actively promote the supply-side reform. With the changes in the economic environment at home and abroad during the "13th Five-Year Plan" period, new demands for the real economy will continue to emerge. Commercial banks should timely grasp the opportunities brought about by supply-side structural reforms, stimulate innovation and business vitality, and accelerate the realization of their leaping development (Shandong Banking Regulatory Bureau Task Force, 2011).

\subsection{Optimizing the Adjustment of Credit Structure}

With the major adjustment of China's industrial structure, credit resources and financial services of commercial banks will be mainly invested in industries and enterprises that represent the structural transformation of the economy, which will help stabilize the quality of credit assets of commercial banks. According to the data provided by the Central Bank, China's bad loans in commercial banks have been serious in recent years. In 2017, the sum of non-performing loans for manufacturing, wholesale sales, and commercial services accounted for more than $80 \%$. However, high-quality new industries require more investment in credit funds, and supply-side structural reforms provide good opportunities. The central government will successively introduce a variety of policies and regulations to stimulate and support the growth of such enterprises, and introduce measures such as targeted tax incentives and financial subsidies, as well as supporting systems. Therefore, commercial banks can grasp this opportunity to encourage capital to flow into emerging industries with high operating efficiency and development potential, increase the importance attached to financing for small and micro enterprises and "agriculture, rural areas and farmers", revitalize stock funds, and greatly increase the efficiency of resource allocation in the financial markets.

\subsection{Actively Enhancing the Driving Force for Innovation}

The main content of "the new normal state" of China's economy is that the mode of economic growth has gradually shifted to innovation-driven change. The data from the Central Bank also shows that from the year of 2012 to 2015, the labor force has been decreasing year by year. The labor shortage has gradually increased and the labor costs have gradually increased. Now it is necessary to change the extensive development model involving the massive investment in human resources and natural resources and to promote sustainable economic development through technological innovation. Therefore, commercial banks should pay more 
attention to the development of new industries and small and micro enterprises, help them in organizing funds and controlling financial costs. Of course, commercial banks bear great risks at the same time. This requires commercial banks to increase their ability to operate funds and increase financial innovation. For example, asset securitization is a good choice. The continuous introduction of Internet companies in the financial industry has had a great impact on the banking industry as a whole, and it has occupied the profit space that originally belonged to the traditional banking industry. In 2012, there is only 200 online loan platforms, but in 2017 there are nearly 6000 , increasing by almost 30 times.

\subsection{Actively Promoting Transnational Operations}

The essence of supply-side reform is to transfer the economic environment to monopoly competition. Commercial banks should promote corporate liquidation and merger and reorganization, guide enterprises to take advantage of opportunities to seize the global market share, form multinational enterprise groups, transfer surplus production capacity and serve domestic companies. According to the theory of Following Customers, the bank's overseas expansion has taken place in response to overseas operations of its home country customers. It is conducting business in host countries and providing customers with $3 \mathrm{~A}$ services. In the international banking industry, following customers are common and there are more and more powerful banks expanding overseas. According to the data provided by the Central Bank, in 2013 there were 620 Chinese banks' overseas branches while in 2017, there were 640 overseas branches established by China Commercial Banks. The data shows that when Chinese companies expand overseas, they need Chinese banks' overseas financial institutions to closely follow and provide various financial services, such as trade financing guarantees, international settlement, etc. Therefore, the scale of expansion of domestic commercial banks overseas and the scale of transnational operation of domestic enterprises complement each other.

\subsection{Steadily Developing Consumer Finance}

In 2015, the national Engel's coefficient was 30.6\%, close to the UN's standard of abundance of $20 \%$ to $30 \%$, and the proportion of consumer spending on per capita traffic, medical care, education, culture, and entertainment increased from $12.3 \%$, $6.9 \%$ and $10.6 \%$ to $13.3 \%, 7.4 \%$ and $11.0 \%$. There are many reasons for the changes in people's consumption structure. First, the population is concentrated from rural areas to towns and cities, and lifestyles are changed. Second, the Internet gives residents a more convenient consumer experience, and low cost and personalization are the advantages of internet platforms. In addition, the most important thing is that consumption escalation is the inevitable result of rising residents' income. The country vigorously promotes supply-side reforms and promotes consumption upgrades. For example, "Camp to increase" and interest rate marketization further reduce the development cost of the service industry and guided social capital to new areas of short-board consumption. Therefore, the development potential of the service industry is enormous. When we see the development potential of the service industry, we must not overlook the development potential of the people's consumption. Commercial banks must accurately position and actively deploy and take the lead in upgrading the market competitive advantages and comprehensive operating capabilities of consumer finance.

\section{Commercial Banks’ Mission to Support Supply-Side Reform}

In the process of promoting the structural reforms on the supply side, commercial banks should also actively abandon the extensive management model that tends to the demand side, increase the total factor productivity of the industry, achieve balance and coordination at both ends of supply and demand, and enhance the quality and effectiveness of economic growth. It should actively provide efficient financial support for the development of the real economy and industrial transformation. While accelerating the upgrading of its own business model, it should also make contributions to China's "13th Five-Year Plan" and economic restructuring.

\subsection{Playing a Market-Oriented Role}

In the current economic situation, loose monetary or fiscal policies cannot be used to effectively stimulate the economy. The era of China's demand-driven economy has come to an end. The overcapacity problem in many industries is prominent. The government is relying on investment promotion or loose monetary policy to stimulate the economy. Its marginal utility is gradually weakening, so commercial banks must seek breakthroughs on the supply side. The past economic reforms were mainly concentrated on the demand side. The current supply-side reforms must insist on both supply and demand. The excessive supply of industries in the market should be limited by the use of commercial bank credit, and the industries that lack demand should be supported with credit. However, the key to the current economic problems is not the lack of total demand, but the fact that the supply structure cannot match the changes in the demand structure. Therefore, the focus of commercial bank loan funds should be gradually changed to market-oriented model and improving the investment effectiveness and accuracy by circumventing the overcapacity industry. 


\subsection{Optimizing Industrial Structure}

The scale of the expansion of commercial banks and its lack of rational supply structure have always been the focus of criticism. According to statistics from the People's Bank of China, the total number of large and medium-sized enterprises in China is only $1 \%$, but it has occupied more than $65 \%$ of the financial resources; the loan coverage rate of domestic commercial banks for enterprises of medium sized or below is less than $5 \%$, which is not only significantly less than 54\% in Europe and America, but also much less than 35\% for enterprises of similar sizes. The serious surplus of backward production capacity has further aggravated the imbalance between market supply and demand and the continuous decline in product prices. The profitability and innovation ability of high-quality enterprises have been inhibited, which has greatly reduced the overall competitiveness of the industry. Therefore, commercial banks should timely and accurately grasp supply-side reform opportunities, decisively transfer credit resources from overcapacity and backward industries, gradually improve the bank's credit structure, transfer credit to emerging and government-supporting industries, and at the same time, we should prevent the emergence of new backward production capacity so as to excavate new profit growth point in real sense.

\subsection{Actively Serving the Real Economy}

In recent years, inadequate financing channels have always inhibited the development of real economy, especially the growth of small and medium-sized enterprises. However, the real economy, as the pillar of the national economy, is subject to financial constraints, which will inevitably lead to economic downturn, lower employment rate, increased tax burden, and the economic deterioration cycle superimposed, eventually leading to the increase of the National economy. Therefore, the return of commercial banks to serve the real economy not only has far-reaching strategic significance, but also has a positive effect on the development of banks. . On the one hand, it is necessary to strengthen the supply of financial resources and the adaptability of various economic entities, such as actively expanding and extending the financial industry chain, equity financing and related supporting investment banks and financial markets, in order to cater to the characteristics of initial projects, high risks and high returns, to promote new technologies that are not yet mature and are still being created, and provide enterprises in the early stage to get enough credit resources in time. On the other hand, commercial banks should also actively expand their investment banking services to minimize corporate loan costs based on assisting enterprises in implementing structured financing, short-term financing bills, and bond underwriting. On the basis of constructing an interest rate rational credit environment, commercial banks must also govern and regulate intermediary businesses, reduce fees and fee rates, so as to promote inclusive finance and expand financing channels for small and micro enterprises.

\subsection{Strictly Controlling Systemic Financial Risks}

Under the background of continued downward pressure on the economy, the local debt crisis and the bad loan conditions of the banks are deteriorating. Strict control over systemic risks is the base of supporting supply-side reforms. As can be seen from Figure 1, the worsening of the current non-performing loans of commercial banks is still intensifying, and it is urgent to strictly control the financial risks of commercial banks.

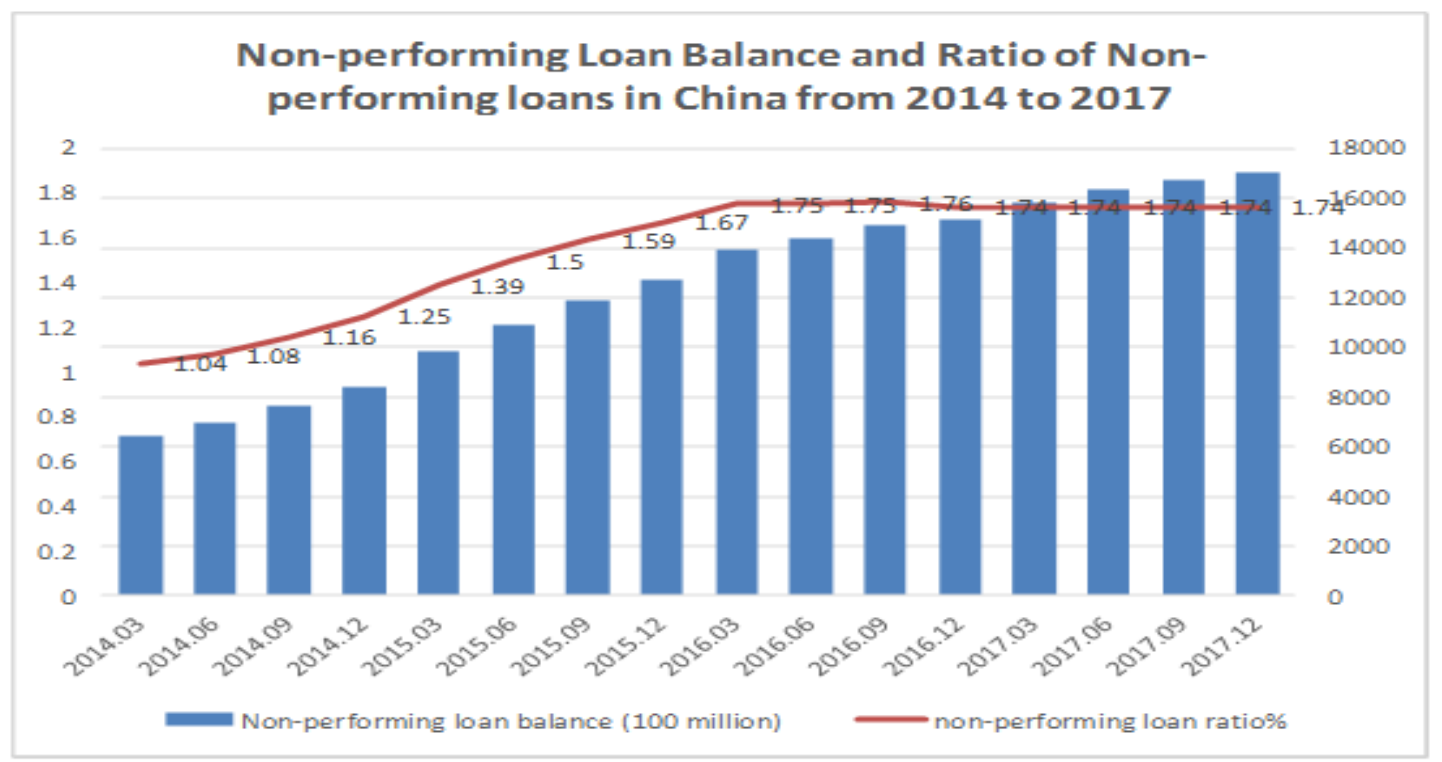

Figure-1. Non-performing Loan Balance and Ratio of Non-performing loans in China from 2014 to 2017. Source: China Banking Regulatory Commission. 
There are two potential current systemic financial risks: local government debt crisis, and all kinds of illegal financing methods. On the one hand, commercial banks need to play their role as local government staff, provide programs or credit support, accelerate the completion of local government debt replacement, improve the full-caliber government debt management mechanism and improve local government bond issuance methods. On the other hand, commercial banks should also establish a multi-dimensional and allround supervision mechanism, guide and standardize various financing methods, regularly or irregularly implement the attack and management of financial risks, always maintain zero tolerance for illegal fundraising, establish a financial risk early warning mechanism, reasonably solve financial illegal cases, and strictly control systematic and regional financial risks. In addition, commercial banks should also guide enterprises to reduce debt ratios, promote the development of direct financing, and assist the government to standardize investment and financing models, so as to ensure the financial order and social and economic stability in various parts of the country.

\section{Countermeasures to Support Supply Side Reform}

Under the background of supply-side reform, commercial banks should also reform. In order to change the extensive operation mode based on demand-side in the past, commercial banks need to increase effective financial capacity supply, optimize the allocation of resources, improve the quality and efficiency of services, and provide strong financial support for the development of real economy and industrial transformation. Specifically, the following points are made:

\subsection{Correcting Distorted Allocation of Financial Resources}

Optimizing the allocation of bank credit resources and correcting distorted allocation of financial resources are key measures to enhance total factor productivity and can effectively serve the transformation and upgrading of China's economy. Firstly, commercial banks should increase their credit support for strategically emerging industries such as "Made in China 2025". During the "Thirteenth Five-Year Plan" period, strategic new industries should be actively deployed, and resources should be concentrated in supporting the Internet, communications networks, aerospace, and bioengineering industries, and boosting domestic emerging industries to accelerate "high-end"; secondly, commercial banks should encourage branch development to promote regional coordination. Based on the long-term planning of the "Belt and Road" initiative during the "13th Five-Year Plan" period, the coordinated development of Beijing-Tianjin-Hebei, and the construction of the Yangtze River Economic Belt, commercial banks should encourage local branches to formulate mid- and long-term strategies according to local characteristics and gradually develop their own distinctive services, distinguished from the differentiated competitiveness of the financial industry, and actively support the implementation of regional key strategic and key projects. Finally, quality service companies should be selected based on market segmentation. According to the state's opinions on industrial restructuring, they should gradually reduce the overproduction of "two high and one surplus", "zombie enterprises" and the proportion of sunset industries in bank credit, and instead actively support industrial restructuring and integration and reorganization, so as to realize the transfer of credit resources from inefficient industries to efficient industries, and keep credit allocation and economic upgrading in the same direction and finalize the adjustment of bank credit structure.

\subsection{Continuously Improving the Competitiveness of Modernization}

China's supply-side structural reforms are based on the twin goals of domestic economic transformation and upgrading and the establishment of an open-economy new system to the outside world. Therefore, the competition between commercial banks during the "13th Five-Year Plan" period will be further intensified. Only by continuously improving its modern competitiveness can we ensure that commercial banks are not at a disadvantage in domestic and international competitions. It is also an important part of ensuring the structural reform of the country's supply side. First of all, it is necessary to continuously improve the bank's operation level, improve the professional quality and service quality of employees, build a solid collaboration and joint guarantee mechanism, and accelerate the improvement of the quality and efficiency level of total factor productivity of commercial banks. Based on the business-oriented line and matrix management, commercial banks should improve existing basic services, establish a sound management system that is compatible with current market conditions and policy regulations, and have a coordination mechanism so as to accelerate the realization of timely response and synergy effect on user demand and market adjustment; secondly, commercial banks should vigorously cultivate and employ talents with professional qualities and complex backgrounds in the field of financial solutions, constantly improve the whole process of sales service system in the foreground, build a reasonable and effective strategy coordination system, professional planning guidance system, timely response to the service security system, so as to timely change production relations, release the productive forces and fully liberate the total factor productivity of the commercial banks. Finally, commercial banks also need to draw lessons from international advanced banks, speed up the integration of internal management, risk control, innovation promotion, technology application and other fields, and take the initiative to transform and upgrade the commercial banks themselves. 


\subsection{Accelerating the Pace of Overseas Direct Investment}

China's four major state-controlled commercial banks and large joint-stock banks have strong financial resources and long-term investment vision. Short-term profits and losses will not have a great impact on the survival and development of banks, so they are more willing to choose the financial markets of developed countries such as Europe and the United States which are more competitive and risky to invest because of competition. At the same time, we can learn many advanced operation experiences. If the commercial banks are limited in their own strength, the demand for the return of foreign investment is more urgent. Therefore, in foreign investment, Chinese banks can focus on providing financial services for foreign enterprises.

\subsection{Digging Deeper into Changes in Customer Demand}

While vigorously promoting improvement on the supply side, we must pay due attention to demand-side management. Especially in the era of continuous integration and innovation of the Internet and various sectors, the needs of bank customers are undergoing tremendous changes. Only by matching financial innovations and service upgrades can new demands be released and new supply be created. In the context of industry convergence and technological change, commercial banks must correctly grasp the development trend of various industries, speed up the shift from focusing on simple "deposit and loan, credit-like" products and tangible services to financial services that adapt to cross-border competition in the industry, such as consulting, intellectualized financial services, so as to meet the new normal. The financial and non-financial needs of bank users are of high standard, such as wealth management, capital operation, enterprise processing scheme consultation, data mining and analysis. On the technical level, commercial banks should actively embrace the technological revolution and the transformation of business concepts in the era of Internet and Internet of Things, improve the overall level of financial services based on mobile interconnection technology; on the business model level, commercial banks should change their business thinking, and build a comprehensive financial and industry co-development service platform, to continuously upgrade the level of professional services, vigorously support the division of labor and cooperation in the industrial and financial service chains, and to adapt to the changing and upgrading needs of bank customers based on applied technology.

\subsection{Encouraging the Development of Entrepreneurial Finance}

Innovation is the driving force behind economic development. Entrepreneurship is also a key way to generate innovation. Only by vigorously promoting the growth of entrepreneurial finance can we effectively overcome the financing difficulties of entrepreneurial innovation. This is also the internal demand for supply side reform. The goal of entrepreneurial finance is based on a series of financial innovations, covering angel funds, new three boards, private equity funds and "four publics" and other methods to truly solve the financing difficulties of start-ups. To promote the rapid development of entrepreneurship finance, it is urgent to speed up the comprehensive operation of commercial banks, provide standardized financial services for the whole process of settlement, credit and consultation, provide preferential financial services for projects with broad growth space and enterprises in line with government development policies, and reduce financing cost appropriately, lower credit conditions. When they are promoting entrepreneurship and innovation of the masses, commercial banks are also significantly expanding the development space. In addition, The main service object of commercial banks should be transferred from positive cash flow, steady growth and positive profit enterprises to enterprises in each life cycle, and give financial resources support to enterprises in each cycle stage.

\subsection{Promoting Inclusive Financial Innovation and Integration}

Along with the integration and innovation of Internet, big data, cloud computing and other technologies and finance, Internet finance has achieved extraordinary growth. It has led the traditional finance to the trend of product differentiation, market segmentation, channel mobile terminal, cross-border integration and normalization. Internet finance has gradually become a driving force for small and micro enterprises. New forces to develop and improve the overall competitiveness of China's financial industry. Although Internet finance has brought about certain impact on traditional finance, commercial banks and Internet finance are not contradictory. Commercial banks should adapt to the needs of the times, speed up the integration and innovation with the Internet, actively develop Internet finance, so as to construct a coordinated development pattern of financial industry. To speed up the development of Internet finance, commercial banks should draw lessons from the following four points: 1) Referring to the big data thinking, the development model of commercial banks will be transformed into "data-driven" based, so as to promote its full play of the value of massive transaction data, through the analysis, collection and combination of large data, to build an efficient customer demand analysis and credit evaluation mechanism; 2) Drawing lessons from the thinking of mobile Internet platform, building a service network based on Internet platform, speeding up the design of bank APP client, thus breaking through the constraints of traditional physical network, and realizing the liquidity acquisition and management of commercial bank customers; 3) Drawing lessons from business logic, focusing on the improvement of customer experience to pursue maximum profits for customers and to achieve a 
substantial increase in customer satisfaction; 4) Drawing lessons from the thinking of Inclusive Finance, helping to solve the plight of serving small and medium-sized enterprises, covering the scope of services to small and micro enterprises, rural consumer groups and traditional inferior customers, providing innovative vitality for the transformation and upgrading of commercial banks, and helping commercial banks further drive the development of real economy.

\subsection{Establishing a Consumer Oriented Financial Model of Consumption}

Firstly, improving product research and development. According to the different consumption needs of different consumers and the increasing demand of education, tourism and entertainment driven by the upgrading of consumption structure of residents, diversified, differentiated and targeted consumer financial products are introduced. At the same time, because of the increasing income of farmers, who account for the majority of our population, commercial banks should develop consumer financial products suitable for rural residents from the aspects of loan interest rate, term, guarantee mortgage, repayment methods to meet the farmers' higher quality of life requirements. Secondly, optimizing management method. We should vigorously promote the brand of consumer finance, enhance our core competitiveness and social influence with brand consumption concept, and greatly enhance customer loyalty and market share. We constantly optimize the business process, streamline the approval process and improve efficiency. Thirdly, preventing risks. The alarm bell of the subprime mortgage crisis is ringing, so we should attach great importance to and guard against risks. We should assess the level of consumer loans, avoid excessive debt and illegal withdrawal of bank funds from false consumer loans, and promote the healthy and sustainable development of consumer finance. At present, China's breakthrough in the bottleneck of economic development is the supply side reform. Commercial banks should recognize the opportunities brought about by the supply-side reform, clarify the direction of the supply-side reform in support of the financial sector, actively implement the requirements of the state on the supply-side reform, actively promote the adjustment of capacity structure, regularly integrate the industries with excess capacity, and strengthen financial innovation, green credit and internal control. Administration.

\subsection{Actively Promoting Green Finance}

With the rapid development of China's economy, environmental issues have gradually emerged, and advocacy for green development has become an inevitable choice. It is also an important part of the "13th Five-Year Plan" and supply-side reforms. Therefore, we must actively develop green finance and reasonably guide financial resources to clean energy, energy-saving transportation and other environmental protection industries. This is not only necessary to improve the environmental situation, but also the urgency of social development. With regard to actively promoting green finance, first, we should build a green financial product system that focuses on light assets based on the new characteristics of green industries. For the emerging green enterprises, commercial banks should implement differentiation strategy and adopt innovative guarantee forms to design targeted financial products such as environmental protection income pledge credit, green financial lease, intellectual property pledge loans and so on. Second, based on the new characteristics of economic structural changes, we should adjust accordingly to achieve the optimization of credit structure. After determining the direction of support and the core industries, we can implement a differentiated and dynamic green credit scheme. At the same time, we should pay close attention to the government's new policies and regulations, industry access threshold and energy-saving and environmental protection regulations, and focus on examining the energy-saving benefits, operability and potential problems of loan projects, so as to prevent the credit risks arising from violating the national economic and environmental protection policies in advance. Finally, we should further deepen the research on "Equator Principles" and international cooperation based on the national macro strategic planning. At present, China has truly become an external investment economy. With the promotion of the strategy of "one belt and one road", the pace of convergence between Chinese enterprises and the world economy will gradually accelerate. Therefore, the growing international financial services of commercial banks will bring more challenges to commercial banks to speed up the integration of international standards and standardize the development of globalization.

\section{Conclusions and Suggestions}

Finance plays a decisive role in the economy, and the introduction of structural reform on the supply side will inevitably lead to a series of new adjustments and changes in the financial system, especially for commercial banks in the context of interest rate marketization, financial inclusiveness, and the sustainable development of Internet finance, which will face many opportunities and challenges. Therefore, commercial banks should actively assume the mission of giving play to the market-oriented role, optimizing the industrial structure, serving the real economy actively and strictly controlling the financial risks, rectifying the distortion of financial resources allocation, continuously improving the modern competitiveness, digging in depth the changes of customer demand, vigorously promoting the development of entrepreneurial finance and Internet finance, integrating innovation and actively advocating green finance. For their own supply-side reform, commercial banks must first throw away the past "debt first" operational objectives. In order to carry 
out consumption upgrading, industrial transformation and structural adjustment in a real sense, commercial banks should make full use of Internet, cloud computing, large data and other technologies to drive the development of real economy and small and micro enterprises based on their own operating characteristics and unique advantages, and give full play to the guiding effect of commercial banks' credit resources to improve financial innovation, integration of industrial transformation and upgrading. In addition, commercial banks also need to build a vertical, flat management system to speed up the automation and standardization of business processes, so as to continuously improve the overall efficiency of their services to the real economy.

\section{References}

Cao, P., \& Li, Z. (2015). Research on the transformation of commercial banks under "the New Normal State". Rural Finance Research, 1, 110-120.

Che, H. (2015). Logic of supply-side structural reform. China Development Watch, 11, 102-111.

Jia, K., \& Su, J. (2014). Two rounds of "negation of negation" experienced by "supply-side" economics schools, evaluation of the "supply-side" school, academic inspiration, and prospects based on China's deliberations. Financial Research, 8 , 83-98.

Lu, J., \& Liu, F. (2014). The choice and change of commercial banks under the background of Internet finance. Southern Finance, 1, 79-86.

Shandong Banking Regulatory Bureau Task Force. (2011). Current China's commercial banks transition trend, characteristics and issues. Financial Development Research, 1, 12-20.

Zhao, Y. (2015). Strengthening supply-side reform January-February financial and financial hotspot observation. Chinese Financier, 12, 199-208. 